\title{
Audits and critical incident reporting in paediatric anaesthesia: lessons from 75,331 anaesthetics
}

\author{
Sharon $\underline{W a n}^{1}$, mMed, Yew Nam Siow ${ }^{1}$, mmed, Su Min Lee ${ }^{1}$, fanzcA, Agnes $\underline{N g}^{1}$, MMed
}

\begin{abstract}
INTRODUCTION This study reports our experience of audit and critical incidents observed by paediatric anaesthetics from 2000 to 2010 at a paediatric teaching hospital in Singapore.

METHODS Data pertaining to patient demographics, practices and critical incidents during anaesthesia and in the perioperative period were prospectively collected via an audit form and retrospectively analysed thereafter.

RESULTS A total of 2,519 incidents were noted at the 75,331 anaesthetics performed during the study period. There were nine deaths reported. The majority of incidents reported were respiratory critical incidents $(n=1,757,69.8 \%)$, followed by cardiovascular incidents $(n=238,9.5 \%)$. Risk factors for critical incidents included age less than one year, and preterm and former preterm children.

CONCLUSION Critical incident reporting has value, as it provides insights into the system and helps to identify active and system errors, thus enabling the formulation of effective preventive strategies. By creating and maintaining an environment that encourages reporting, we have maintained a high and consistent reporting rate through the years. The teaching of analysis of critical incidents should be regarded by all clinicians as an important tool for improving patient safety.
\end{abstract}

Keywords: anaesthesia, audit, complications, critical incidents, paediatric

Singapore Med J 2013; 54(2): 69-74

\section{INTRODUCTION}

Critical incident reporting is a system where incidents and near misses are described and analysed. ${ }^{(1)}$ A critical incident is defined as 'any event that affected, or could have affected, the safety or the quality of care of the patient whilst under the care of an anaesthetist'.(1) This system was first described by Flanagan in the 1950s as a technique to improve safety and performance among military pilots. ${ }^{(2)}$ In 1978, Cooper et al used a modified critical incident technique in which they interviewed anaesthetists and obtained descriptions of preventable incidents. ${ }^{(3)}$ Anaesthesia has since been at the forefront in the use of critical incident reporting to improve patient safety. ${ }^{(4)}$ There are many established critical incident reporting programmes worldwide, such as the American Society of Anesthesiologists (ASA) Committee on Patient Safety and Risk Management, Anesthesia Patient Safety Foundation and National Patient Safety Agency in the United Kingdom, and the Australian Incident Monitoring System in Australia..$^{(4,5)}$

We reviewed the critical incidents in paediatric anaesthesia at our institution and analysed the factors associated with them. This study reports our experience of audit and critical incidents observed in paediatric anaesthetics from 2000 to 2010 at a paediatric teaching hospital in Singapore.

\section{METHODS}

We undertook a retrospective analysis of prospectively collected audit data of all anaesthetics and reported critical incidents between January 1, 2000 to December 31, 2010. Institutional review board approval was obtained for the study, with waiver of informed consent. The reports were checked for duplication and wrong data entry. The paediatric anaesthesia department at KK Women's and Children's Hospital, Singapore, has had an audit system in place since 1997, where an audit form is filled out for every paediatric patient that requires the care of an anaesthetist. Critical incidents were recorded on a structured questionnaire and as free text on the reverse of these forms. Information was entered in paper form in the operation theatre and subsequently transferred to an electronic database. Data from these forms were stored securely on the hospital's computer network. All critical incidents were discussed at departmental meetings in order to identify the risk factors and learning points that had led to the incidents. Applicable changes were implemented to prevent the future occurrence of such incidents, thus improving patient safety. We also undertook a descriptive analysis of the data collected.

\section{RESULTS}

A total of 2,519 critical incidents out of 75,331 anaesthetics performed were reported over the 11-year period. The incidence of reporting of critical incidents was 3.3\%. Table I describes the demographics of our patients. The age of the children ranged from 1-day old neonates to young adults with existing congenital diseases. A majority of the patients, accounting for $78.9 \%$ of total incidents, were healthy ASA I or II children. Most surgeries were elective procedures (80.5\%). 65 (6.5\%) neonates had a critical

${ }^{1}$ Department of Paediatric Anaesthesia, KK Women's and Children's Hospital, Singapore

Correspondence: Dr Sharon Wan, Associate Consultant, Department of Paediatric Anaesthesia, KK Women's and Children's Hospital, 100 Bukit Timah Road, Singapore 229899. yuankwan28@yahoo.com.sg 
Table I. Characteristics of total anaesthetics $(n=75,331)$ and critical incidents $(n=2,519)$.

\begin{tabular}{|c|c|c|c|c|}
\hline \multirow[t]{2}{*}{ Characteristic } & \multicolumn{2}{|c|}{ No. of patients } & \multirow{2}{*}{$\begin{array}{c}\text { Critical incidents/ } \\
\text { total anaesthetics (\%) }\end{array}$} & \multirow{2}{*}{$\begin{array}{l}\text { Critical incidents/ } \\
\text { total incidents (\%) }\end{array}$} \\
\hline & Total anaesthetics & Critical incidents & & \\
\hline \multicolumn{5}{|l|}{ ASA status } \\
\hline 1 & 48,507 & 1,183 & 2.4 & 47.0 \\
\hline$\|$ & 20,035 & 804 & 4.0 & 31.9 \\
\hline III & 6,243 & 474 & 7.5 & 18.8 \\
\hline IV & 519 & 50 & 9.6 & 2.0 \\
\hline V & 27 & 8 & 29.6 & 0.3 \\
\hline \multicolumn{5}{|l|}{ Age } \\
\hline Neonate & 1,006 & 65 & 6.5 & 2.6 \\
\hline Infant & 9,328 & 643 & 6.9 & 25.5 \\
\hline Child aged $>1$ year & 64,997 & 1,811 & 2.7 & 71.9 \\
\hline \multicolumn{5}{|l|}{ Weight } \\
\hline$<2 \mathrm{~kg}$ & 645 & 63 & 9.7 & 2.5 \\
\hline $2-10 \mathrm{~kg}$ & 12,378 & 793 & 6.4 & 31.5 \\
\hline $10-20 \mathrm{~kg}$ & 27,325 & 882 & 3.2 & 35.0 \\
\hline$>20 \mathrm{~kg}$ & 34,983 & 781 & 2.2 & 31.0 \\
\hline \multicolumn{5}{|c|}{ Gestational maturity at birth } \\
\hline Premature & 231 & 44 & 19.1 & 1.8 \\
\hline Ex-premature & 466 & 81 & 17.3 & 3.2 \\
\hline Full term & 74,634 & 2,394 & 3.2 & 95.0 \\
\hline \multicolumn{5}{|l|}{ Type of surgery } \\
\hline Emergency & 13,443 & 492 & 3.6 & 19.5 \\
\hline Elective & 61,888 & 2,027 & 3.2 & 80.5 \\
\hline
\end{tabular}

Note:ASA I: normathe systemic disease that is a constant threat to life; ASA V: moribund patient who is not expected to survive without the operation.

ASA: American Society of Anesthesiologists

incident reported. Infants aged between 1 month and 1 year had a critical incident rate of $6.9 \%$, but chi-square test revealed no significant difference between the two age groups. Infants and children weighing $<10 \mathrm{~kg}$ had a higher critical incident rate.

Table II provides a description of all the critical incidents reported during the study period. Respiratory events were the most reported critical incident $(n=1,757)$, accounting for $69.8 \%$ of the total critical incidents (Fig. 1). The most commonly reported respiratory event was laryngospasm, which accounted for $50.2 \%$ of all respiratory incidents. Two patients who had laryngospasm developed negative pressure pulmonary oedema and required postoperative intensive care unit (ICU) ventilation and monitoring. The second most reported event was hypoxia due to causes other than laryngospasm. Hypoxia is defined as inadequate oxygen to the body tissues and can manifest as a fall in saturation, cyanosis or drop in partial pressure of oxygen on arterial blood gas analysis. Of the 181 incidents of bronchospasm, 16 were associated with hypoxia. Other respiratory events included difficult airway $(n=22)$, aspiration $(n=22)$ and hypercapnia $(n=8)$. Other events reported included central apnoea, breath-holding, hypoventilation and stridor.

A total of 238 cardiovascular critical incidents were reported. The most common cardiovascular incident was hypotension $(40.3 \%)$, of which seven incidents were associated with haemorrhage and nine incidents with arrhythmias. There were 11 incidents of near cardiac arrest reported. Nine neurological events were reported, which included seizures, myoclonic jerks, cerebral spinal fluid leakage, awareness and delayed extubation secondary to drowsiness. Miscellaneous critical incidents consisted of reports such as pain service issues and miscommunication
- one included a case where a parent swallowed her child's oral premedication. Nine intraoperative deaths were reported. Four of these patients had severe cyanotic congenital heart disease and died intraoperatively from complications of the disease. Four deaths were related to surgical complications, with one patient having severe neonatal sepsis while undergoing extracorporeal membrane oxygenation annulations.

\section{DISCUSSION}

The overall critical incident reporting rate in our study was $3.3 \%$, which is similar to that reported in other studies (range $2.4 \%-3 \%){ }^{(6-17)}$ The average annual rate of critical incident reporting at our hospital is $3 \%-4 \%$ (Fig. 2), and this percentage has remained stable through the years despite an increase in patient numbers.

Infants and neonates below one year of age have a higher risk of having a critical incident, reported to be 2.5 times that of older children. ${ }^{(15-17)}$ In our study, premature infants and ex-premature children had a four-fold increased risk of anaesthetic complications. This finding is similar to that of other studies. ${ }^{(16,18,19)}$ The decreased physiological reserve of premature infants is known to contribute to a higher rate of anaesthetic complications. Risk factors can also be attributed to the infants' small size and the more complex surgeries. Ex-premature children are also likely to have underlying congenital or chronic diseases resulting from their prematurity. Patients with ASA V status were also at higher risk of critical incidents. ASA $\vee$ status is defined as a moribund patient who is not expected to survive without surgery. Therefore, the underlying physiology of these patients put them at higher risk of adverse events. 
Table II. Description of critical incidents.

\begin{tabular}{|c|c|}
\hline Description of critical incidents & No. of critical incidents (\%) \\
\hline Airway and respiratory events* & 1,757 \\
\hline Hypoxia & $678(38.6)$ \\
\hline Laryngospasm & $883(50.2)$ \\
\hline Bronchospasm & $181(10.3)$ \\
\hline Difficult airway & $22(1.2)$ \\
\hline Aspiration & $22(1.2)$ \\
\hline Hypercapnia & $8(0.4)$ \\
\hline Others & $55(3.1)$ \\
\hline Cardiovascular events* & 238 \\
\hline Haemorrhage & 27 (11.3) \\
\hline Hypertension & $6(2.5)$ \\
\hline Hypotension & $96(40.3)$ \\
\hline Arrhythmia & $92(38.6)$ \\
\hline Cardiac arrest/near cardiac arrest & $11(4.6)$ \\
\hline Others & $29(12.2)$ \\
\hline Pharmacological events & 100 \\
\hline Drug reaction & $40(40.0)$ \\
\hline Medication error & $45(45.0)$ \\
\hline Blood product & $11(11.0)$ \\
\hline Others & $4(4.0)$ \\
\hline Equipment-related events & 183 \\
\hline Anaesthetic machine & $21(11.4)$ \\
\hline Circuit & $37(20.2)$ \\
\hline $\begin{array}{l}\text { Airway equipment/ } \\
\text { endotracheal tube }\end{array}$ & $22(12.0)$ \\
\hline Monitors & $10(5.4)$ \\
\hline Vascular devices & $23(12.5)$ \\
\hline Others & $70(38.3)$ \\
\hline latrogenic events & 83 \\
\hline Dental & $37(44.5)$ \\
\hline Airway & $3(3.6)$ \\
\hline Pressure & $10(12.0)$ \\
\hline Burns & $5(6.0)$ \\
\hline Others & $28(33.7)$ \\
\hline Metabolic events & 16 \\
\hline Glucose & $2(12.5)$ \\
\hline Hypothermia & $13(81.2)$ \\
\hline Hyperthermia & $0(0)$ \\
\hline Others & $1(6.2)$ \\
\hline Neurological events & 9 \\
\hline Procedural complications & 78 \\
\hline Arterial puncture & $7(9.0)$ \\
\hline Dura puncture & $1(1.3)$ \\
\hline Local anaesthetic toxicity & $0(0)$ \\
\hline Venous tap & $0(0)$ \\
\hline Haematoma & $7(9.0)$ \\
\hline Visceral injury & $11(14.1)$ \\
\hline Haemothorax/pneumothorax & $6(7.6)$ \\
\hline Neurological deficit & $1(1.3)$ \\
\hline Others & $45(57.7)$ \\
\hline Death & 9 \\
\hline Other events & 37 \\
\hline
\end{tabular}

${ }^{*}$ Note: 123 patients had more than one concurrent critical incident.

The most common critical incidents reported were respiratory events, followed by cardiovascular events. This trend has been well established in other published critical incident reports as well, with the rates of reported respiratory incidents ranging between $1.9 \%$ and $18.8 \%{ }^{(8,9,14,15,17)}$ Unlike the adult population where cardiovascular events form the majority of critical incidents, respiratory events are more frequent in children due to differences in the anatomy of the paediatric airway and their respiratory physiology. Children have a relatively large tongue, a floppy and more cephalic epiglottis, and a subglottic region that is the narrowest part of the paediatric airway. All of these put them at a greater risk of upper airway obstruction. They also have a smaller respiratory reserve because of their smaller functional residual capacity, leading to a greater risk of hypoxia.

A majority of respiratory incidents were contributed by laryngospasm, which accounted for $50.2 \%$ of all respiratory incidents. Laryngospasm is defined as glottis closure due to reflex constriction of the laryngeal muscles. Our reporting rate was much higher than other published data, ${ }^{(14,15)}$ as all laryngospasms, with or without hypoxia, were reported in our study. It is also possible that the diagnostic criteria used for laryngospasm in our study may have differed from those used by other studies. Contributory factors for laryngospasm included inadequate anaesthesia, especially during the induction and emergence phases, upper respiratory tract infections and a junior anaesthesia provider.

The less common but clinically significant events were also analysed. There were 11 cases of near cardiac arrest reported. This incidence was comparable to that of published studies on cardiac arrest. ${ }^{(20,21)}$ In one ASA I patient who was scheduled for elective scoliosis surgery, complications resulted due to massive haemorrhage. Of the ten remaining patients who had statuses of ASA III and above, nine underwent cardiac procedures for complex cyanotic heart disease. Most studies have found that children younger than one year old, those with more severe underlying diseases (ASA II-V), those with underlying cardiac disease and those requiring emergency surgeries have worse outcomes after cardiac arrest. ${ }^{(20)}$

There were 22 incidents of aspiration/regurgitation in our series, accounting for $0.02 \%$ of the total anaesthetics. There were no mortalities in our series and none of the patients required ICU admission. In 2005, Kluger et al reported the rate of aspiration and regurgitation in children to be $0.1 \%{ }^{(22)}$ The risk factors reported to be associated with aspiration and regurgitation in children include greater severity of disease (ASA III-V), intravenous induction and emergency procedures. ${ }^{(23,24)}$ According to Kluger et al, the mortality rate following aspiration varies between 1 in 35,000 to 1 in $72,000 .{ }^{(22)}$ Other sequelae such as laryngospasm, desaturation and bronchospasm can also occur.

A total of 36,471 regional anaesthetics were performed during the study period. It is the practice at our institution, as in many other children's hospitals, to perform all regional blocks under general anaesthesia. $34(0.09 \%)$ critical incidents were directly related to regional anaesthetics, which was comparable to the $0.12 \%$ and $0.09 \%$ overall complication rates reported by Polaner and Drescher ${ }^{(25)}$ and Giaufre et al, respectively. ${ }^{(26)} \mathrm{A}$ majority of our critical incidents were related to complications of the penile nerve and ilioinguinal blocks. Other complications included urethra injury $(\mathrm{n}=7)$ and wrong block side $(\mathrm{n}=8)$. A system change was made for site markings prior to induction in 2009, following which no further case of regional block on the wrong side was encountered. According to the latest reviews on regional anaesthesia in children, the rate of serious complications from 


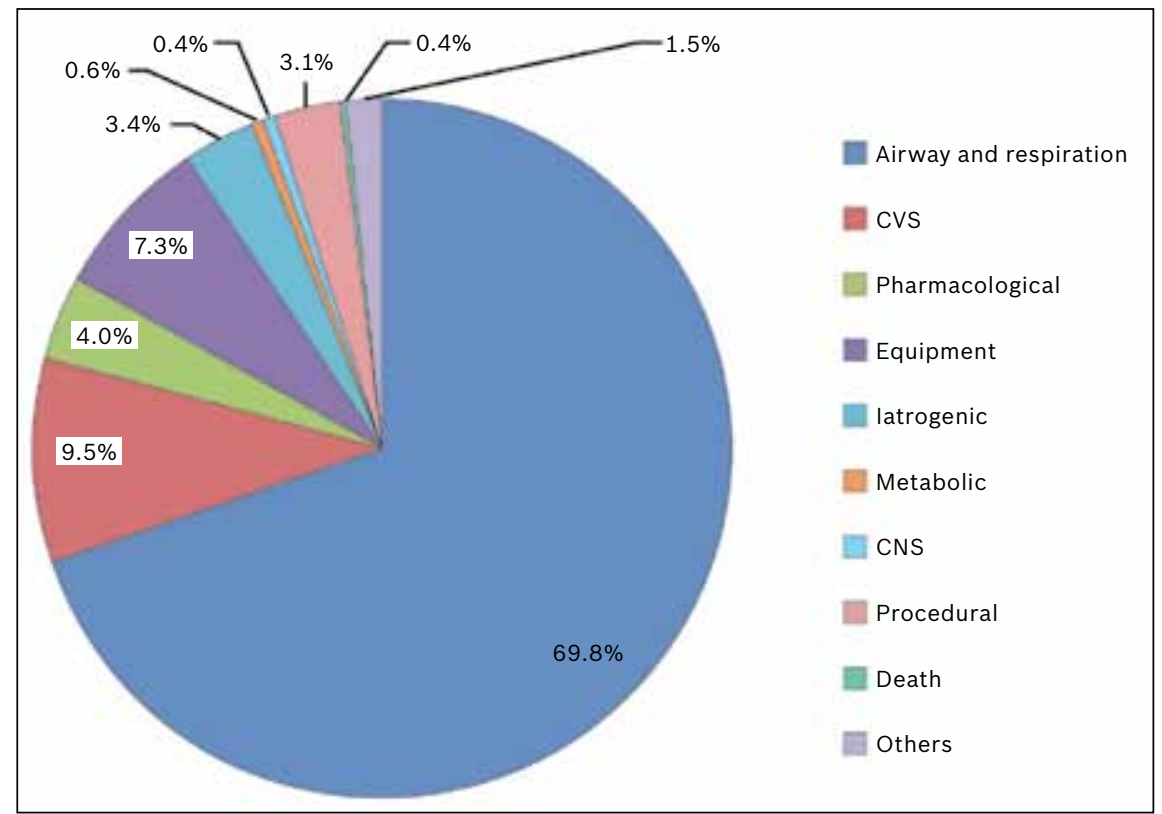

Fig. 1 Pie chart shows the distribution of critical incidents from 2000 to 2010.

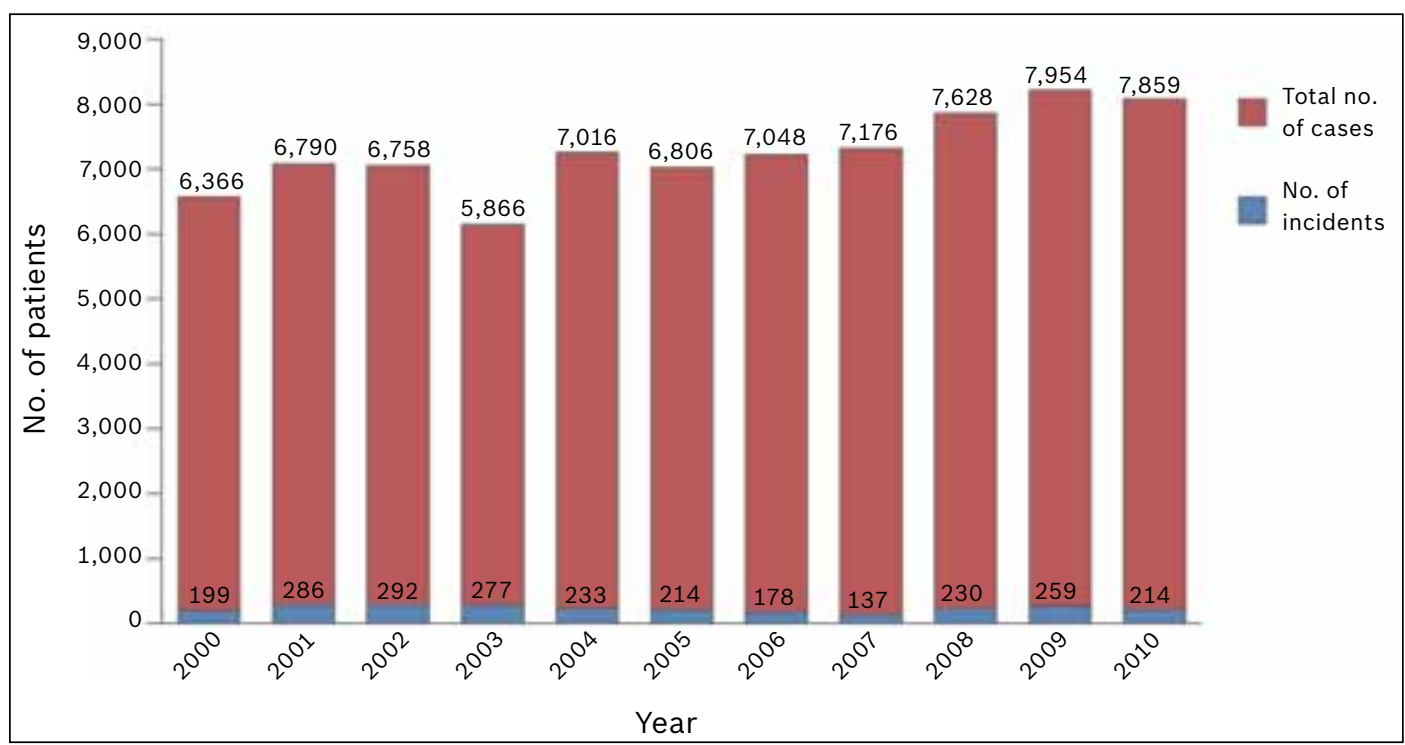

Fig. 2 Bar graph shows the annual incidence of critical incidents reported from 2000 to 2010.

epidural/caudal blocks is now $0.04 \% .{ }^{(25-27)}$ In our study, only one patient had dura puncture from caudal anaesthesia. In three patients, the epidural catheter was misplaced.

Hypothermia accounted for $81.2 \%$ of all metabolic critical incidents. 11 of 13 such incidents occurred in infants aged less than one year. Infants and neonates have a higher body surface areato-weight ratio, thus predisposing them to higher risks of heat loss. These incidents were investigated and discussed with the surgical and neonatology departments, and preventive strategies have been implemented. These included: (a) the use of sterile plastic adhesive drapes to prevent conductive heat loss from wet, cold drapes; (b) operating directly on the open care plan for neonates, which has an overhead heating device; and (c) control of operation theatre temperatures. The incidence of hypothermia decreased subsequent to these adjustments from five in 2009 to zero in 2010.

Pharmacology-associated incidents accounted for $4.0 \%$ of the total number of incidents. Medication error, defined as any preventable event that may cause or lead to inappropriate medication use or patient harm, accounted for $45.0 \%$ of all pharmacology-associated incidents. It has been cited as the commonest incident in recent articles on critical incidents, with reported rates ranging between $13 \%$ and $35 \% .{ }^{(14,17)}$ The differences in these findings might be attributable to the relatively more sophisticated system in place for capturing medication errors in some of these institutions. System changes that have been implemented in our institution include the discontinuation of the use of heparin $5,000 \mathrm{IU} / \mathrm{mL}$ vial following the occurrence of medication errors involving similar-looking rocuronium and heparin vials.

There were 183 incidents of equipment-associated critical incidents in our study. These included incidents with anaesthesia machines, circuits, airway equipment, monitors and vascular devices. Specific faults and malfunctions in equipment were corrected immediately. In critical incidents involving specific 
equipment, preventive strategies, including exploring alternatives, were implemented. For example, when repeated incidents of circuit disconnection in our paediatric humidifier circuit were encountered, an alternative humidifier circuit was sourced and subsequently replaced the old system.

In all, 123 patients had more than one critical incident, all of which were associated with a respiratory event. 54 incidents were respiratory incidents resulting in cardiovascular sequelae, such as bradycardia and hypotension. The remaining incidents were associated with instances where the primary critical incident, such as equipment-, aspiration- or pharmacology-related incidents, resulted in a respiratory event.

The main criticism regarding incident reporting is that it is a voluntary system. ${ }^{(4-6)}$ The data collected are assumed to be an underestimation of the true number of critical incidents. The reasons put forth for anaesthetists not reporting the true number of critical incidents include, but are not limited to, fear of blame, and lack of time, feedback and ownership of the reporting system. ${ }^{(5)}$ Other factors that have been described to limit reporting were organisational factors (such as lengthy forms or insufficient time), fear of punitive actions, lack of feedback, unfamiliarity with the process and lack of clarity on what should be reported. ${ }^{(5)}$

Our institution has established an environment that is conducive for incident reporting. We have designed an audit form that is easy to fill out and takes less than five minutes to complete. These audit forms, which are available in every operation theatre, are filled out for each patient and subsequently entered into a secure hospital database, with all descriptive data typed out and stored. Anonymity is maintained when cases are put up for discussion. Critical incidents are discussed during regular departmental meetings, which forms an important feedback mechanism that promotes reporting. When a critical incident is deemed to have had significant impact, it is immediately singled out for additional analysis to formulate effective preventive measures. If an event falls under the category of our hospital's clinical indicator, the incident is reported to the hospital's clinical quality assurance committee, which then undertakes a structured analysis. The analysis of critical incidents is taught in our department in order to inculcate a culture of patient safety. Trainees are taught to use critical incident analysis as a method to look into the gaps and inadequacies of the system, as well as to suggest preventive measures.

An area in need of improvement at our hospital would be the reporting of near misses - only four patients were reported to have had near misses over the 11-year study period. While near misses are incidents that have had no adverse effect on the patient, reporting them would have enabled system errors to be picked up early and their recurrence prevented. For instance, in one case, a labelled syringe filled with bupivacaine was mistaken for thiopentone, although the error was picked up prior to the injection being administered to the patient. Analysis of the incident revealed a system gap, in which both the labels for thiopentone and bupivacaine were grey. A change of label colours was made to be consistent with international standards: yellow for induction medication and grey for local anaesthetics. Education and encouragement of staff to report near misses should increase the accounting of such incidents.

While education and sharing of critical incidents play an important role in enhancing patient safety, further improvements could be effected with formal analysis and the tracking of active and system errors. This would not only allow for tracking of the various critical incidents but also indicate improvement after an intervention has been made. It is the belief of the authors that setting up a national critical incident reporting system, such as that in the UK and Australia, will enhance patient safety within and across local hospitals. Analysis of the number and kinds of incidents reported could be performed at the national level and disseminated widely and quickly. This would have the advantage of highlighting areas for improvement while also triggering further focus by national organisations on prospective actions such as raising awareness, research, audits, training initiatives, specific curriculum and guideline modifications.

In conclusion, critical incident reporting is valuable, as it provides insights into the healthcare system and aids in the identification of active and system errors, thus enabling the formulation of effective preventive strategies. The teaching of analysis of critical incidents should be regarded by all clinicians as an important tool that could help improve patient safety.

\section{REFERENCES}

1. Woods DM, Johnson J, Holl JL, et al. Anatomy of a patient safety event: a pediatric patient safety taxonomy. Qual Saf Health Care 2005; 14:422-7.

2. Flanagan JC. The critical incident technique. Psychol Bull 1954; 51:327-58.

3. Cooper JB, Newbower RS, Long CD, McPeek B. Preventable anesthesia mishaps: a study of human factors. Anesthesiology 1978; 49:399-406.

4. Choy CY. Critical incident monitoring in anaesthesia. Curr Opin Anaesthesiol 2008; 21:183-6.

5. Mahajan RP. Critical incident reporting and learning. Br J Anaesth 2010; 105:69-75.

6. Bell G. Lessons for paediatric anesthesia from audit and incident reporting. Paediatr Anaesth 2011; 21:758-64.

7. Marcus R. Human factors in pediatric anesthesia incidents. Paediatr Anaesth 2006; 16:242-50.

8. Cohen MM, Cameron CB, Duncan PG. Pediatric anesthesia morbidity and mortality in the perioperative period. Anesth Analg 1990; 70:160-7.

9. Edomwonyi NP, Ekwere IT, Egbekun R, Eluwa B. Anesthesia-related complications in children. Middle East J Anesthesiol 2006; 18:915-27.

10. Irita K, Tsuzaki K, Sawa T, et al. [The state of pediatric anesthesia in Japan: an analysis of the Japanese society of anesthesiologists survey of critical incidents in the operating room]. Masui 2007; 56:93-102. Japanese.

11. Van der Walt JH, Sweeney DB, Runciman WB, Webb RK. The Australian Incident Monitoring Study. Paediatric incidents in anaesthesia: an analysis of 2000 incident reports. Anaesth Intensive Care 1993; 21:655-8.

12. Morray JP, Geiduschek JM, Caplan RA, et al. A comparison of pediatric and adult anesthesia closed malpractice claims. Anesthesiology 1993; 78:461-7.

13. Kakavouli A, Li G, Carson MP, et al. Intraoperative reported adverse events in children. Paediatr Anaesth 2009; 19:732-9.

14. MacLennan AI, Smith AF. An analysis of critical incidents relevant to pediatric anesethesia reported to the UK National Reporting and Learning System, 2006-2008. Paediatr Anaesth 2011; 21:841-7. 
15. Murat I, Constant I, Maud'huy H. Perioperative anaesthetic morbidity in children: a database of 24,165 anaesthetics over a 30-month period. Paediatr Anaesth 2004; 14:158-66.

16. Tay $\mathrm{CL}$, Tan GM, Ng SB. Critical incidents in paediatric anaesthesia: an audit of 10,000 anaesthetics in Singapore. Paediatr Anaesth 2001; 11:711-8.

17. Jimenez N, Posner KL, Cheney FW, et al. An update on pediatric anesthesia liability: a closed claims analysis. Anesth Analg 2007; 104:147-53.

18. William JM, Stoddart PA, Williams SA, Wolf AR. Post-operative recovery after inguinal herniotomy in ex-premature infants: comparison between sevoflurane and spinal anaesthesia. Br J Anaesth 2001; 86:366-71.

19. Krane EJ, Haberkern CM, Jacobson LE. Postoperative apnea, bradycardia, and oxygen desaturation in formerly premature infants: prospective comparison of spinal and general anesthesia. Anesth Analg 1995; 80:7-13.

20. Morray JP, Geiduschek JM, Ramamoorthy C, et al. Anesthesia-related cardiac arrest in children: the initial findings of the Paediatric Perioerative Cardiac Arrest (POCA) Registry. Anesthesiology 2000; 93:6-14.

21. Tibballs J, Kinney S. A prospective study of outcome of in-patient paediatric cardiopulmonary arrest. Resuscitation 2006; 71:310-8.
22. Kluger MT, Visvanathan T, Myburgh JA, Westhorpe RN. Crisis management during anaesthesia: regurgitation, vomiting, and aspiration. Qual Saf Health Care 2005; 14:e4.

23. Borland LM, Sereika SM, Woelfel SK, et al. Pulmonary aspiration in pediatric patients during general anesthesia: incidence and outcome. J Clin Anesth 1998; 10:95-102.

24. Neelakanta G, Chikyarappa A. A review of patinets with pulmonary aspiration of gastric contents during anesthesia reported to the Deparmental Quality Assurance committee. J Clin Anesth 2006; 18:102-7.

25. Polaner DM, Drescher J. Paediatric regional anesthesia: what is the current safety record? Paediatr Anaesth 2011; 21:737-42.

26. Giaufré E, Dalens B, Gombert A. Epidemiology and morbidity of regional anesthesia in children: a one-year prospective survey of the FrenchLanguage Society of Pediatric Anesthesiologists. Anesth Analg 1996; 83:904-12.

27. Polaner DM, Bosenberg A Cravero J, et al. Preliminary data from the Pediatric Regional Anesthesia Network (PRAN): demographics, practice patterns and complications. ASA Annual Meeting New Orleans; New Orleans, 2009.

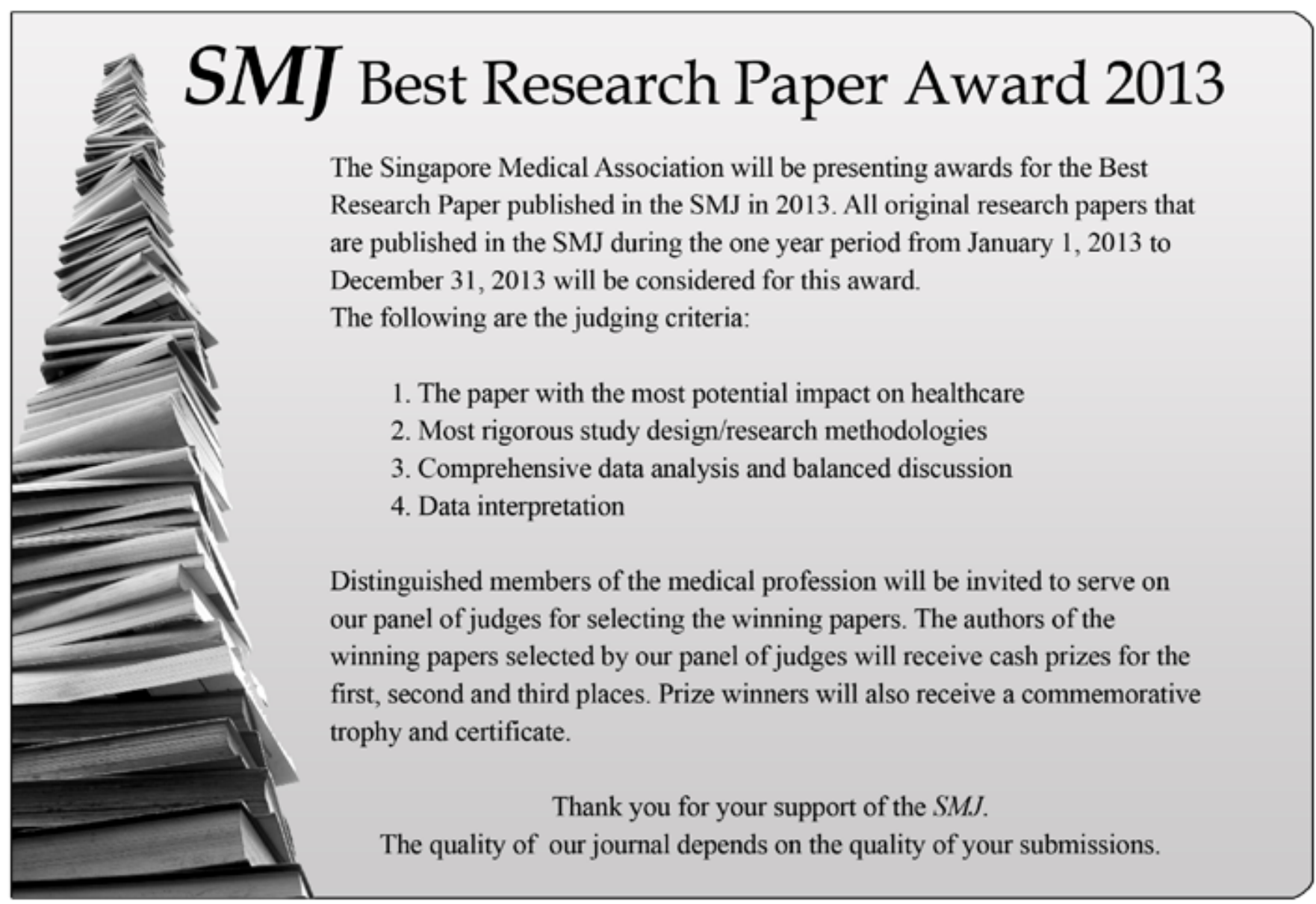

